\title{
Functional State of Endothelium in Aging
}

\author{
Viktoriia Yu Zharinova*, Bodretskaya L, Duzhak G, Samot SI, Shapovalenko I and Voinarovskaya G \\ The Institute of Gerontology, Ukraine
}

*Corresponding author: Viktoriia Yu Zharinova, The Institute of Gerontology, Kyiv, Ukraine

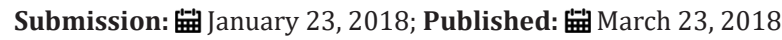

\section{Introduction}

It is known that the older age is an independent non-modifiable risk factor for the development of cardiovascular pathology. An important role in the development of cardiovascular pathology in the older age is played by age-dependent changes in the structure and function of the endothelium [1]. The deterioration of the functional state of the endothelium an important role in the development of vascular pathology. Literatura suggest that endothelial dysfunction is a factor that precedes vascular pathology and provokes its development $[2,3,4]$. It was found that endothelial damage is a pathogenetic link of diseases of the cardiovascular system. Thus, changes in the endothelium of endocardial micro vessels lead to a decrease of myocardial fibers contractility [5], a clear relationship of pressure in the left ventricular cavity from nitric oxyde NO synthesis [6]. Endothelin-1 has been shown to be an autocrine-paracrine factor in the development of myocardial hypertrophy $[7,8]$.

The leading role of the endothelium in the formation of mechanisms of ischemic preconditioning in the development of ischemia/reperfusion is defined [9]. Suwaidi and his colleagues [10] found, that in patients with impaired endothelium-dependent vasodilatation, destabilization events occur 2-3 times more frequently than patients with a relatively preserved function of the endothelium. Similar data are given by Matsuzava [11,12] \& Widmer [13] and other. A disturbance of the endothelium of the microvascular of the myocardium is an indicator of an increased risk of heart attack and sudden death. Also shown the leading role of the endothelium in the development of ischemic coronary syndrome with unchanged coronary arteries [14]. Thus, the disturbance of the functional state of the endothelium is a risk factor and the leading pathogenetic mechanism of the development of vascular pathology, and not only atherosclerotic genesis $[7,8,15]$. However, studies on age-related changes in the endothelium primarily address certain aspects of this issue $[5,16]$. At the same time it is important to study the different functions of the endothelium in each examined man. Considering this, in this work we have studied the functional state of the vascular endothelium in healthy older adults in comparison with younger healthy adults.

\section{Material and Methods}

Were studied healthy people of different ages: 30 people aged 60-74 years and 28 people aged $30-44$ years. Selection in the groups was carried out on the basis of an anamnesis, the data from current clinical, instrumental and laboratory examinations. The patients were examined in the department of cardiology of the Institute of Gerontology. Clinical examination included: collection of complaints, anamnesis, visual examination, auscultation. Instrumental methods of examination included: ECG, X-ray of lungs, ultrasound of abdominal cavity organs, echocardiography, transcranial vessels doppler with estimation of intima-media thickness, 24-hour ECG monitoring, treadmill test. Laboratory methods: general analysis of blood, urine, biochemical blood test, glucose level, lipidogram, markers of inflammation, electrolytes.

A group of healthy people aged 60-74 years included people who have been observed at the Institute of Gerontology for more than 10 years (recruitment of patients into groups occurred in the period 2016-2017). According to the results of a thorough examination, they had physiological changes corresponding to age and hadn't acute and chronic diseases of any etiology. The second group included volunteers aged 30-44. According to the results of the clinical and instrumental examination, they hadn't had any diseases.

The study of the functional state of the endothelium was carried out using laser Doppler flowmetry on the Transonik apparatus (USA) according to the method developed by Zharinova (Lishnevska) V, Duzak G (patent No. 2001074868). Was estimated the volumetric velocity (VV) of the skin's blood flow in the region of the middle third of the inner surface of the forearm in the initial state, and also after the functional test with reactive hyperemia.

The amount of NO was evaluated based on the determination of the stable $\mathrm{NO}_{2}$ metabolite (nitrite anion) using a Griss reagent by the method of Green et al. [17]. The content of prostacyclin (6-ketoPG-F1), thromboxane A2 (TxB2), in blood plasma was determined by immunoassay using ELISA KIT, RDS, UK (Lot 02K016C и 03T010A). The level of interleukin (IL) $1 \beta, 4,6$, and tumor necrosis factor (TNF- $\alpha$ ) was studied by enzyme immunoassay using Pro Con immunoassay test systems (000 "Proteonovycontur", Russia). The level of P-selectine was studied using immunoassay test systems the sP-select in ELISA KIT, Bender Med Sus (Austria) (Lot 936013) and level VCAM-1was studied using immunoassay test systems VCAM-1 ELISA KIT, Diaclone (France) (Lot 834313). The level of VEGF in the blood serum was determined by the method of enzyme 
immunoassay (IFA) for an additional set of reagents in the Bender Med Systems GmbH (Austria). The received data were processed with the help of the computer program "Excel1" and Statistic-8.0.

\section{Results of the Study}

The results of this study showed that the maximum the volumetric velocity of the skin's blood flow at the peak of reactive hyperemia in the older adults is lower than in younger adults. Older adults had a long latent period prior to the start of the reaction, the duration of the reaction is reduced (Table 1). The reason for the reduced maximum volume flow velocity is a disruption of the ratio of endothelial vasoconstrictors and vasodilators. According to the received data, the level of stable metabolite $\mathrm{NO}-\mathrm{NO}_{2}$ in older adultsis reliably reduced $(16,71,3 \mathrm{nmol} / \mathrm{l}$ in group 30 -44 years and $8,4 \pm 1$, $1 \mathrm{nmol} / \mathrm{l}$ in group 60-74 years, $\mathrm{p}<0,05)$ and 6-ketoPG-F1(232, $8 \pm 16,1 \mathrm{mmol} / \mathrm{l}$ in group $30-44$ years and $184,4 \pm 11,2 \mathrm{mmol} / \mathrm{l}$ in group 60-74 years, $\mathrm{p}<0,05)$. At the same time, in the plasma of the older adults the level of endothelin- 1 and tromboxan A2 is increased-endotelin-1 -4, $1 \pm 0,2 \mathrm{pmol} / \mathrm{l}$ in group 30-44 years and 6, $2 \pm 0,2 \mathrm{pmol} / \mathrm{l}$ in group 60-74 years, $\mathrm{p}<0,01$; and thromboxane A2$265,1 \pm 21,3 \mathrm{mmol} / \mathrm{l}$ in group 30-44 years and396, $4 \pm 19,5 \mathrm{mmol} / \mathrm{l}$ in group 60-74 years, $\mathrm{p}<0.01$ (Table 2).

Table 1: Change in the volumetric velocity of the skin's blood flow in healthy people of different ages when carrying out a test with reactive hyperemia.

\begin{tabular}{|c|c|c|c|c|}
\hline \multirow{2}{*}{ Group } & \multicolumn{3}{|c|}{ Parameter } \\
\hline & \multirow{2}{*}{ Initial VV, ml/min x100g } & Max VV & Latent Period, & \multirow{2}{*}{ Duration Reaction, sec } \\
\cline { 3 - 4 } & & $\mathbf{m l} / \mathbf{m i n x 1 0 0 g}$ & $5,51 \pm 0,03$ & $109,5 \pm 6,3$ \\
\hline 30-44years & $2,40 \pm 0,02$ & $6,5 \pm 0,03$ & $9,50 \pm 0,03$ & $88,5 \pm 3,3$ \\
\hline 60-74 years & $1,60 \pm 0,01$ & $5,2 \pm 0,01$ & $<0,05$ & $<0,05$ \\
\hline P value & $<0,01$ & $<0,01$ & & \multirow{2}{*}{} \\
\hline
\end{tabular}

Table 2: Age differences in the level of individual vaso active substances synthesized by the endothelium.

\begin{tabular}{|c|c|c|c|}
\hline \multirow{2}{*}{ Parameter } & \multicolumn{2}{|c|}{ Groups } & \multirow{2}{*}{ P value } \\
\cline { 2 - 3 } & $\mathbf{3 0 - 4 4}$ years & $\mathbf{6 0 - 7 4}$ years & \\
\hline Endotelin-1 $(\mathrm{pmol} / \mathrm{l})$ & $4,1 \pm 0,2$ & $6,2 \pm 0,2$ & $<0,01$ \\
\hline $\mathrm{NO}_{2}(\mathrm{nmol} / \mathrm{l})$ & $16,7 \pm 1,3$ & $8,4 \pm 1,1$ & $<0,05$ \\
\hline 6-ketoPG-F $(\mathrm{mmol} / \mathrm{l})$ & $232,8 \pm 16,1$ & $184,4 \pm 11,2$ & $<0,05$ \\
\hline Tromboxan $\mathrm{A}_{2}(\mathrm{mmol} / \mathrm{l})$ & $265,1 \pm 21,3$ & $396,4 \pm 19,5$ & $<0,01$ \\
\hline
\end{tabular}

A sing of impaired protective function of the endothelium in older adults is a decrease in the level of anti-inflammatory cytokines (IL-4-42, $5 \pm 1,1 \mathrm{pg} / \mathrm{ml}$ in group 30-44 year and 37 , $3 \pm 1,4 \mathrm{pg} / \mathrm{ml}$ in group $60-74$ years, $\mathrm{p}<0,05$ ) and an increase in the level of adhesive molecules (sVCAM - 768,5 $\pm 24,6 \mathrm{ng} / \mathrm{ml}$ in group $30-44$ years and $1243,7 \pm 15,1 \mathrm{ng} / \mathrm{ml}$ in group $60-74$ years, $\mathrm{p}<0,05$;

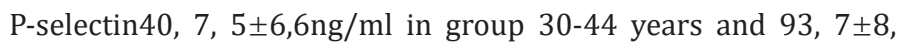
$1 \mathrm{ng} / \mathrm{ml}$ in group 60-74 years, $\mathrm{p}<0,05$ ). These adhesion molecules characterize the degree of interaction of the endothelium with leukocytes and platelets (Table 3). In addition, an important role in the rupture of the endothelium is a property of increasing the level of TNF- $\alpha$ (Table 3). Interesting data were obtained when studying the level of VEGF. It was shown that in healthy older adults there was an increase in VEGF compared to groups of younger adults which may be related to the need to maintain normal perfusion in conditions of age-dependent changes in metabolism of organs and tissues (Table 4). Thus, the results obtained indicate a disruption of vasomotor, synthesizing, antithrombotic, anti-inflammatory endothelial functions in aging. These changes in the functional state of the endothelium are, of course, an important prerequisite for development of vascular pathology in the elderly and require further study in order to develop ways to correct endothelial dysfunction as one of the ways of preventing cardiovascular diseases in the older age group.
Table 3: The level of interleukins, TNF-a adhesive molecules in the plasma of the examined people.

\begin{tabular}{|c|c|c|c|}
\hline \multirow{2}{*}{ Parameter } & \multicolumn{2}{|c|}{ Groups } & \multirow{2}{*}{ P value } \\
\cline { 2 - 3 } & $\mathbf{3 0 - 4 4}$ years & $\mathbf{6 0 - 7 4}$ years & \\
\hline IL-1 $\beta(\mathrm{pg} / \mathrm{ml})$ & $24,4 \pm 0,2$ & $25,3 \pm 1,6$ & $>0,05$ \\
\hline IL- 6(pg/ml) & $30,7 \pm 2,2$ & $32,6 \pm 2,1$ & \\
\hline TNF- $\alpha(\mathrm{pg} / \mathrm{ml})$ & $27,7 \pm 1,3$ & $34,2 \pm 1,1$ & $<0,05$ \\
\hline IL 4(pg/ml) & $42,5 \pm 1,1$ & $37,3 \pm 1,4$ & $<0,05$ \\
\hline sVCAM(ng/ml) & $768,5 \pm 24,6$ & $1243,7 \pm 15,1$ & $<0,05$ \\
\hline P-selectin(ng/ml) & $40,7,5 \pm 6,6$ & $93,7 \pm 8,1$ & $<0,05$ \\
\hline
\end{tabular}

Table 4: The level of VEGF in the serum of blood of the examined people.

\begin{tabular}{|c|c|c|c|}
\hline \multirow{2}{*}{ Parameter } & \multicolumn{2}{|c|}{ Groups } & \multirow{2}{*}{ P value } \\
\cline { 2 - 3 } & $\mathbf{3 0 - 4 4}$ years & $\mathbf{6 0 - 7 4}$ years & \\
\hline VEGF, пг/мл & $220,25 \pm 7,51$ & $233,21 \pm 7,49$ & $<0,05$ \\
\hline
\end{tabular}

\section{Discussion}

The aging process introduces significant changes in the functioning of various organs and systems of the human body [13]. As evidenced by the data obtained during the work, significant changes are also taking place in the endothelium during aging. An important reason for the disruption of the vasoactive function of the endothelium during aging may be a change in the morphology of the endothelial cells, a violation of the energy and reparative processes in them. Although endotheliocytes are a short-lived, selfrenewing cell population, there are data on significant changes in the morphology of cellular systems during aging-a change in the structure and function of mitochondria, the lipid and fatty acid composition of cellmembranes, and the configuration of the receptor cell proteins $[15,18,19]$. This leads to a change in the functional capabilities of cellular systems, including endotheliocytes. 
It is known that one of the most important substances synthesized by endothelium is the endothelial relaxation factor (NO). NO inherent in vasodilatation, anti-adhesive, anti-inflammatory and antioxidant properties $[4,16,20]$. Therefore, the obtained data on the disturbance of the ability of the endothelium to synthesize NO is very important. The results of our study are consistent with the experimental data showing that the ability of the endothelium to synthesis of endothelial relaxation factor decreases with age $[6,21]$. Evaluation of the state of the prostacyclin/thromboxane system has made it possible to evaluate the ratio of humoral vasodilators and constrictors in the blood plasma of the elderly and to obtain additional information on the state of the endothelial vasorelaxant system, because the biological role of prostacyclin and its vasodilating effect differ somewhat from the mechanism of action of NO [2,3].

Deterioration of the protective properties of the endothelium promoted activation and adhesion of platelets and leukocytes. This is evidenced by an increased level of adhesive molecules in the blood of older people. It should be noted that the anti-inflammatory and anti-proliferative properties of the intact endothelium are considered very important from the standpoint of modern concepts of the pathogenesis of diseases. In addition, it was found that, simultaneously with participation in inflammatory reactions, TNF- $\alpha$ increases the level of total cholesterol, very low density lipoprotein cholesterol (VLDL), and lowers the level of high-density lipoprotein (HDL) cholesterol. Clinical evidence of the significance of TNF in the onset of hypertriglyceridemia has been obtained $[22,23]$. That is, an increase in the level of TNF in healthy elderly people is a risk factor for the development of vascular pathology of atherosclerotic origin.

An important role in maintaining the normal level of capillarity and oxygen supply of tissues is the sufficient activity of physiological compensatory angiogenesis, which depends on the proangiogenic activity of the endothelium. It is known that the level of vascular endothelial growth factor is a proven indicator of angiogenesis activity. Increased expression of VEGF triggers a cascade of complex and interrelated reactions that lead to the initiation of angiogenesis, the appearance of new vessels, increased tissue vascularization, and improved perfusion. Conversely, inadequate VEGF production or medication blocking of VEGF (eg, in malignant tumors) causes apoptosis of the endothelium [24,25]. This leads to obstruction of the lumen of the vessels and a significant reduction in the density of the capillary network, contributes to an increase in the total peripheral resistance and the occurrence of perfusion disorders $[24,25]$.

Therefore, the data obtained by us on the increased level of VEGF in the blood plasma of elderly people testify to the preserved compensatory possibilities of the activation system of angiogenesis activation and maintenance of a sufficient level of tissue capillarization. There are contradictions in the data on the state of proangiogenic activity of the endothelium during aging [26]. This may be due to the difference in samples and the individual characteristics of older people. Thus, the data presented in the study characterize the functional state of the endothelium during aging, indicating multidirectional age-dependent changes in individual functional systems of endotheliocytes that can play both a protective and pathological role. These data are important for the development of the correct strategy for the prevention and treatment of cardiovascular pathology in the elderly.

\section{Conclusion}

A. During aging, the vasomotor function of the endothelium is disrupted, as evidenced by a decrease in the maximum the volumetric velocity of the skin's blood flow at the peak of reactive hyperemia, a decrease in the level of endothelial vasodilators NO and prostacyclin and an increase in the level of endothelin-1 and thromboxane A2.

B. There is a disturbance of the protective properties of the endothelium in aging, as evidenced by a decrease in the level of anti-inflammatory cytokines as the level of THP and adhesion molecules increases.

C. In elderly people, the proangiogenic activity of the endothelium is preserved-the level of VEGF increases with age in accordance with physiological needs.

\section{References}

1. Fleg JL, Aronow WS, Frishman WH (2011) Cardiovascular drug therapy in the elderly: benefits and challenges. Nat Rev Cardiol 8(1): 13-28.

2. Bonetti PO, Lerman LO, Lerman A (2003) Endothelial dysfunction: a marker of atherosclerotic risk. Arterioscler Thromb Vasc Biol 23(2): $168-175$.

3. Busse R, Fleming L (2003) Endothelial dysfunction in atherosclerosis. J Vasc Res 23(Suppl 1): 181-194

4. Gonzalez MA, Selwyn AP (2003) Endothelial function, inflammation, and prognosis in cardiovascular disease. Am J Med 8A: 99S-106S.

5. Rivard A, Fabre JE, Silver M, Chen D, Murohara T, et al. (1999) Agedependent impairment of angiogenesis. Circulation 99(1): 111-120.

6. Rudic D, Sessa W (1999) Nitric oxide in endothelial dysfunction and vascular remodeling: Clinical correlates and experimental links. Am J Hum Genet 64(3): 673-677.

7. Amiri F, Virdis A, Neves MF, Iglarz M, Seidah NG, et al. (2004) Endothelium-restricted overexpression of human endothelin-1 causes vascular remodeling and endothelial dysfunction. Circulation 110(15): 2233-2240.

8. Goettsch W, Lattmann T, Amann K, Szibor M, Morawietz H, et al. (2001) Increased expression of endothelin- 1 and inducible nitric oxide synthase isoform II in aging arteries in vivo: implications for atherosclerosis. Biochem Biophys Res Commun 280(3): 908-913.

9. Qin Yang, Guo Wei He, Malcolm John Underwood, Cheuk Man Yu (2016) Cellular and molecular mechanisms of endothelial ischemia/reperfusion injury: perspectives and implications for postischemic myocardial protection. Am J Transl Res 8(2): 765-777.

10. Suwaidi JA, Hamasaki S, Higano ST, Nishimura RA, Holmes DR, et al (2000) Long-term follow-up of patients with mild coronary artery disease and endothelial dysfunction. Circulation 101(9): 948-954.

11. Matsuzawa Y, Guddeti RR, Kwon TG, Lerman LO, Lerman A (2015) Secondary prevention strategy of cardiovascular disease using endothelial function testing. Circ J 79(4): 685-694 
12. Matsuzawa Y, Lerman A (2014) Endothelial Dysfunction and Coronary Artery Disease: Assessment. Prognosis and Treatment. Coron Artery Dis 25(8): 713-724.

13. Thomasona HA, Hardman MJ (2009) Delayed wound healing in elderly people. Reviews in Clinical Gerontology 19: 171

14. Hurst T, Olson TH, Olson LE, Appleton CP (2006) Cardiac syndrome X and endothelial dysfunction: new concepts in prognosis and treatment. Am J Med 119(7): 560-566.

15. Brandes RP, Fleming I, Busse R (2005) Endothelial aging. Cardiovasc Res May 66(2): 286-294.

16. Lyons D, Roy S, Patel M, Benjamin N, Swift CG (1997) Impaired nitric oxide-mediated vasodilatation and total body nitric oxide production in healthy old age. ClinSci (Lond) 93: 519-525.

17. Green L, Wannger D, Glogowska I (1982) Analisis of nitrate and $\left[\mathrm{N}_{15}\right]$ nitrate in biological fluids. Analit. Biochem 126: 131-138.

18. Cat H, Harrison D (2000) Endothelial dysfunction in cardiovascular diseases: the role of oxidant stress. Circ Res 87(10): 840-844.

19. d'Uscio LV, Barton M, Shaw S, Luscher TF (2000) Endothelin in atherosclerosis: importance of risk factors and therapeutic implications. J Cardiovasc Pharmacol 35(4 Suppl): S55-S59.
20. Kubes P, Suzuki M, Granger DN (1991) Nitric oxide: an endogenous modulator of leukocyte adhesion. Proc Natl AcadSci U S A 88(11): 46514655 .

21. Hoffmann J, Haendeler J, Aicher A, Rössig L, Vasa M, et al. (2001) Aging enhances the sensitivity of endothelial cells toward apoptotic stimuli: important role of nitric oxide. Circ Res 89(8): 709-715.

22. Jeffrey R, Curtis, Ani John (2012) Onur Baser Dyslipidemia and Changes in Lipid Profiles Associated With Rheumatoid Arthritis and Initiation of Anti-Tumor Necrosis Factor Therapy Arthritis. Care \& Research 64(9): 1282-1291.

23. Yang LH, Chen DF (2007) Effects of TNF alpha on the expression of SCAP and triglyceride contents in cultured steatotic hepatocytes. Zhonghua Gan Zang Bing Za Zhi 15(10): 767-770.

24. Niu G, Chen X (2010) Vascular endothelial growth factor as an antiangiogenic target for cancer therapy. Curr Drug Targets 11(8): 10001017.

25. Taimeh Z, Loughran J, Birks EJ, Bolli R (2013) Vascular endothelial growth factor in heart failure. Nat Rev Cardiol 10(9): 519-530.

26. Widmer R, Lerman A (2014) Endothelial dysfunction and cardiovascular disease. Glob Cardiol Sci Pract 2014(3): 291-308.
Creative Commons Attribution 4.0

International License

For possible submissions Click Here

\section{Submit Article}

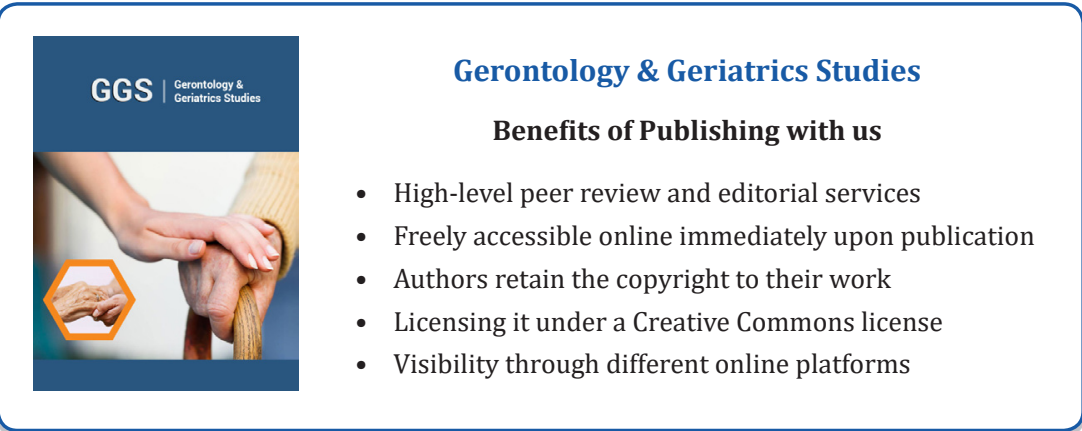

